\title{
PENERAPAN SISTEM JOB ORDER COSTING DALAM PENENTUAN HARGA JUAL PRODUK PADA CV. SATU SATU MEDIA UTAMA
}

\author{
Anggelika S. Nangin ${ }^{1}$, Grace B. Nangoi ${ }^{2}$, Victorina Z. Tirayoh ${ }^{3}$ \\ 1,2,3 Jurusan Akuntansi, Fakultas Ekonomi dan Bisnis, Universitas Sam Ratulangi, Jl. Kampus Bahu, Manado, \\ 95115, Indonesia \\ E-mail : anggelikasnangin@gmail.com
}

\begin{abstract}
$C V$. Satu Satu Media Utama in calculating the cost of the product, has not calculated carefully, causing problems for the company that are unknown in detail and impact the selling price of the company's products. CV. Satu Satu Media Utama is a company engaged in Digital Printing Industry. This study aims to determine the role of Job Order Costing in determining the selling price of the product, using the method of calculating Full Costing and Variable Costing. Method of data analysis used in this research is descriptive qualitative. The results of research for the implementation of Job Order Costing system, the company has applied in the collection of product cost, but in the calculation of the cost of the company's products does not include marketing costs and depreciation costs of the machine into the calculation of overhead costs, and the company has not entered the price card of the order as the auxiliary card in the determination product selling price.
\end{abstract}

Keywords: Job order costing, factory overhead cost, selling price

\section{PENDAHULUAN}

Perhitungan harga pokok produk menjadi biaya yang penting dalam memperhitungkan harga jual barang produksi suatu perusahaan. Ketelitian dalam memperhitungan harga pokok produk menjadi suatu faktor yang penting dalam kesuksesan suatu perusahaan, agar dapat mengkontrol biaya-biaya apa saja yang mungkin terlalu besar atau kecil dalam proses produksi dan mampu bersaing dengan perusahaan lainnya secara sehat. Perhitungan biaya produk yang dikeluarkan perusahaan untuk menghasilkan suatu produk haruslah akurat, sehingga perusahaan dapat menentukan harga jual yang kompetitif di pasar global saat ini. Perusahaan sering kali mengabaikan perhitungan biaya produk secara akurat yang dapat mengakibatkan harga jual barang perusahaan tersebut tidak mampu bersaing dipasaran.

Dalam perhitungan harga pokok produk ada dua cara pengumpulan yang dapat digunakan, yaitu process costing dan job order costing. Process costing adalah penentuan harga pokok produk yang digunakan dalam situasi dimana produksi hanya melibatkan satu produk tunggal saja dan dibuat dalam satu jangka yang lama atau diproduksi secara terusmenerus. Contoh perusahaan manufaktur semen, besi, tepung, bensin dan perusahaan bahan baku lainnya. Sedangkan job order costing merupakan cara pengumpulan harga pokok produk untuk barang atau produk yang dibuat berdasarkan pesanan. Apabila suatu pesanan diterima segera dikeluarkan perintah untuk membuat produk tersebut sesuai dengan spesifikasi masing-masing pesanan.

Barang yang dipesan khusus pelanggan akan dibuat sesuai dengan waktu yang telah disepakati bersama, sehingga perusahaan harus memperhitungkan harga jual barang berdasarkan pesanan secara akurat. Seorang pelanggan atau konsumen seringkali sangat memperhatikan harga dalam membuat keputusan pembelian atau pemesanan produk apakah ia akan membeli suatu produk atau tidak yang sesuai dengan kemampuan ekonominya. Walaupun tidak jarang kualitas lebih diunggulkan daripada harga, namun tidak dapat 
dipungkiri bahwa banyak konsumen yang lebih mempertimbangkan harga dalam proses keputusan pembelian barang konsumen.

\section{TINJAUAN PUSTAKA}

Akuntansi Manajemen. Menurut Siregar, dkk (2013 : 1) mendefinisikan akuntansi manajemen sebagai proses mengukur, mengakumulasi, menyiapkan, menganalisis, dan mengkomunikasikan kejadian ekonomi yang digunakan oleh manajemen untuk pengambilan keputusan. Salman dan Farid (2017 : 4) menyatakan bahwa, akuntansi manajemen adalah penerapan konsep dan metode yang tepat dalam mengolah data ekonomi masa lalu dalam membuat proyeksi masa depan suatu usaha untuk membantu manajemen dalam penyusunan rencana perusahaan dan pengambilan keputusan untuk mencapai tujuan tersebut.

Harga Pokok Produksi. Menurut Bustami dan Nurlela (2013 : 49) harga pokok produksi adalah kumpulan biaya produksi yang terdiri dari bahan baku langsung, tenaga kerja langsung, dan biaya overhead yang ditambah dengan persediaan barang dalam proses awal dan dikurangi persediaan barang dalam proses akhir. Menurut Hansen dan Mowen (2009 : 60) mengemukakan harga pokok produksi adalah total seluruh biaya-biaya yang digunakan dalam membuat atau memproduksi suatu barang. Biaya yang dipakai untuk produksi barang dihitung perusahaan secara teliti agar dapat menentukan harga pokok produksi yang akurat.

Metode Pengumpulan Harga Pokok Produksi. Menurut Mulyadi (2015 : 17) metode pengumpulan harga pokok produksi sangat ditentukan oleh cara produksi. Untuk memproduksi suatu produk, dibagi menjadi dua metode yaitu:

a. Proccess Costing. Metode ini digunakan oleh perusahaan yang berproduksi secara terus menerus untuk persediaan gudang atau perusahaan yang tidak membuat barang produksi berdasarkan pesanan.

b. Job Order Costing. Metode ini digunakan oleh perusahaan yang memproduksi barang berdasarkan pesanan atau sesuai dengan keinginan konsumen. Biasanya perusahaan yang menggunakan metode ini memproduksi barang terputus-putus sesuai dengan pesanan yang masuk.

Metode Penentuan Harga Pokok Produksi. Metode penentuan harga pokok produksi yaitu suatu cara untuk memperhitungkan unsur-unsur biaya ke dalam harga pokok produk. Terdapat dua pendekatan dalam perhitungan harga pokok produk:

a. Full Costing. Menurut Mulyadi (2015 : 125), harga pokok produksi memperhitungkan semua unsur biaya produksi ke dalam harga pokok produksi yang ditambah dengan biaya non produksi yaitu biaya pemasaran dan biaya administrasi umum.

\section{Tabel 1. Metode Harga Pokok Produksi Full Costing}

\begin{tabular}{|ll|}
\hline Biaya bahan baku & $\mathrm{xx}$ \\
Biaya tenaga kerja langsung & $\mathrm{xx}$ \\
Biaya overhead pabrik variabel & $\mathrm{xx}$ \\
Biaya overhead pabrik tetap & $\underline{\mathrm{xx}}$ \\
Harga pokok produksi & $\underline{\mathbf{x x}}$ \\
\hline
\end{tabular}

Sumber: Mulyadi (2015: 125) 
b. Variable Costing. Menurut Mulyadi (2015 : 127), Variable Costing merupakan metode penentuan harga pokok produksi yang memperhitungkan biaya produksi yang berperilaku variabel.

Tabel 2. Metode Harga Pokok Produksi Variable Costing

\begin{tabular}{|ll|}
\hline Biaya bahan baku & $\mathrm{xx}$ \\
Biaya tenaga kerja langsung & $\mathrm{xx}$ \\
Biaya overhead pabrik variabel & $\underline{\mathrm{xx}}$ \\
Harga pokok produksi & $\underline{\mathbf{x x}}$ \\
\hline
\end{tabular}

Sumber: Mulyadi (2015: 127)

Penerapan Job Order Costing dalam Menentukan Harga Pokok Produk. Menurut Supriyono (2013 : 105), dalam penerapan Job Order Costing diperusahaan, pengakumulasian biaya produksi dihitung berdasarkan pesanan. Perhitungan harga pokok produk untuk setiap pesanan melalui Job Order Costing yang diterapkan perusahaan dapat dilaksanakan dengan baik. Untuk mengetahui bagaimana Job Order Costing berperan dalam kaitannya dengan tujuan perhitungan harga pokok produk, maka terdapat gambaran sebagai berikut:

1. Titik pokok penerapan job order costing adalah perusahaan yang memproduksi sesuai dengan spesifikasi dan jumlah yang ditentukan oleh pemesan dari setiap pesanan tersebut dihitung harga pokok produksi untuk setiap pesanan.

2. Dalam penggolongan harga pokok produksi dibagi menjadi dua yaitu biaya produksi langsung yang terdiri dari biaya bahan baku, biaya tenaga kerja langsung dan biaya produksi tidak langsung yang sering disebut overhead.

3. Biaya produksi langsung dihitung sebagai harga pokok produksi berdasarkan biaya yang sesungguhnya terjadi yaitu biaya bahan baku dan biaya tenaga kerja langsung.

4. Harga pokok produk akan dihitung jika pesanan telah selesai dikerjakan dan adanya buku pembantu kartu harga pokok pesanan. Perhitungan harga pokok produksi setiap pesanan, memungkinkan untuk dilaksanakan oleh perusahaan dengan menggunakan metode pengumpulan job order costing agar menghasilkan keandalan informasi perhitungan harga pokok produksi.

\section{METODE PENELITIAN}

Jenis Penelitian. Dalam penelitian ini, peneliti menggunakan jenis penelitian kualitatif dengan analisis deskriptif. Penelitian kualitatif lebih menekankan pada proses dan analisisnya. Sedangkan analisis deskriptif, menyajikan fakta secara sistematik agar mudah untuk dipahami dan disimpulkan yang berupa kata-kata tertulis atau lisan dari orang-orang atau perilaku yang diamati peneliti. Menurut Sugiyono (2017 : 15) metode penelitian kualitatif adalah mendeskripsikan atau memberikan gambaran terhadap objek penelitian yang diteliti melalui sampel atau data yang telah terkumpul dan membuat kesimpulan yang berlaku umum.

Tempat dan Waktu Penelitian. Tempat penelitian ini dilakukan di CV. Satu Satu Media Utama, yang berlokasi di Jl. Yos Sudarso Paal 2 Manado Sulawesi Utara. Waktu penelitian dilakukan pada bulan Maret sampai Mei 2018. Selama waktu penelitian dilaksanakan kegiatan pengumpulan data, pengolahan data dan analisis data. 


\section{Jenis dan Sumber Data}

\section{Jenis Data.}

Data yang digunakan peneliti yaitu data kualitatif dan kuantitatif.

1. Data kualitatif dalam penelitian ini adalah sejarah perusahaan, visi dan misi perusahaan dan produk yang diproduksi perusahaan.

2. Data kuantitatif dalam penelitian ini adalah data-data yang diambil dari perusahaan berupa biaya-biaya produksi perusahaan yang dibutuhkan oleh peneliti.

\section{Sumber Data}

Sugiyono (2015 : 137) menyatakan bahwa pengumpulan data dapat menggunakan dua sumber data yaitu sumber data primer dan sekunder.

1. Data primer adalah sumber data yang diperoleh atau dikumpulkan langsung oleh orang yang melakukan penelitian.

2. Data sekunder merupakan sumber yang tidak langsung memberikan data kepada pengumpul data. Dalam penelitian ini, sumber data yang digunakan peneliti yaitu data primer data yang diperoleh atau dikumpulkan langsung dari objek penelitian (CV. Satu Satu Media Utama).

\section{Metode Pengumpulan Data}

Teknik pengumpulan data dalam penelitian ini, ada 3 teknik yaitu:

1. Observasi atau pengamatan, yaitu pengambilan data dan informasi yang relevan, yang dilakukan oleh peneliti dengan cara mengamati secara langsung semua proses kegiatan yang terjadi dalam perusahaan.

2. Wawancara, yaitu data yang dikumpulkan dengan cara melakukan tanya jawab secara langsung sehingga diperoleh data dan informasi yang akurat. Wawancara yang dilakukan dalam penelitian ini yaitu wawancara langsung dengan pemilik perusahaan Bpk. Wendy Ibrahim. Adapun daftar pertanyaan yang ditanyakan peneliti: (1) bagaimana sistem Job Order Costing pada CV. Satu Satu Media Utama?; (2) bagaimana perhitungan harga jual produk spanduk dan brosur pada CV. Satu Satu Media Utama?

3. Dokumentasi, yaitu teknik pengumpulan data dan informasi dari sumber-sumber tertulis melalui buku, jurnal dan informasi lainnya dari internet dengan melakukan penelitian terhadap catatan atau dokumen yang ada seperti sejarah perusahaan, struktur organisasi dan prosedur akuntansi yang berkaitan serta dokumen pendukung lainnya yang dijadikan pelengkap dan referensi penelitian.

\section{Metode dan proses analisis}

1. Metode Analisis

Metode analisis data yang digunakan yaitu: analisis deskriptif. Menurut Sugiyono (2015 : 105) metode analisis deskriptif, yaitu dengan cara mengumpulkan data-data yang sesuai dengan fakta yang ada dalam penelitian agar dapat dianalisis dan dapat memberikan gambaran tentang masalah yang ada.

\section{Proses Analisis}

1. Meminta laporan perhitungan harga pokok produk perusahaan.

2. Menghitung harga pokok produk menggunakan metode full costing dan variable costing.

3. Membandingkan perhitungan harga pokok produk.

4. Menarik kesimpulan dan memberikan saran. 


\section{HASIL PENELITIAN DAN PEMBAHASAN}

\subsection{Hasil Penelitian}

\section{Penerapan Sistem Job Order Costing}

a. Berdasarkan Pesanan. Perusahaan menerima atau membuat pesanan jika ada konsumen yang memesan barang produksi. Perusahaan tidak membuat pesanan untuk stok persediaan barang digudang, tetapi perusahaan membuat pesanan untuk konsumen yang memesan barang produksi sesuai dengan desain yang diinginkan. Barang yang dipesan akan diselesaikan sesuai dengan kesepakatan waktu dengan konsumen. Sifat produksinya terputus-putus karena sesuai dengan pesanan yang masuk.

b. Penggolongan Biaya Produksi. Perusahaan menggolongkan biaya produksi mereka dengan menghitung biaya bahan baku yang dipakai untuk memproduksi barang langsung dan biaya untuk tenaga kerja langsung. Perusahaan juga memasukkan biaya tidak terduga lainnya serta biaya pemasaran dan administrasi umum.

c. Harga Pokok Produk. Perusahaan dalam perhitungan harga pokok produk sudah menentukan dengan biaya per meter atau per lembar. Perusahaan tidak menghitung harga pokok produk berdasarkan setiap pesanan yang masuk, tetapi perusahaan telah menentukannya terlebih dahulu sehingga perusahaan tidak menggunakan kartu pembantu atau kartu harga pokok pesanan untuk menentukan harga jual produk. Dalam penelitian ini, perhitungan harga pokok produk perusahaan, diambil dua produk yang dipesan konsumen yaitu spanduk (210 Meter) dan brosur (1.000 Lembar). Perhitungan harga pokok produk meliputi biaya bahan baku, biaya tenaga kerja langsung dan biaya overhead pabrik. Berikut perhitungan harga pokok produk menurut perusahaan untuk penentuan harga jual produk.

Tabel 3. Biaya Bahan Baku Pesanan Spanduk (210 Meter)

\begin{tabular}{|l|l|l|l|c|}
\hline No. & \multicolumn{1}{|c|}{ Keterangan } & $\begin{array}{c}\text { Kebutuhan per } \\
\text { Bulan }\end{array}$ & $\begin{array}{c}\text { Biaya per } \\
\text { Meter/Liter/Satuan }\end{array}$ & Jumlah \\
\hline 1. & Kain MMT Bahan China & 210 meter & Rp. 7.000/ meter & Rp. 1.470 .000 \\
\hline 2. & Tinta Ink & 2 Liter & Rp. $500.000 /$ liter & Rp. 1.000 .000 \\
\hline 3. & Gromment & 150 biji & Rp. $3.000 /$ satuan & Rp. 450.000 \\
\hline & Total & & & Rp. 2.920.000 \\
\hline
\end{tabular}

Sumber: CV. Satu Satu Media Utama

Tabel 3 menunjukkan biaya bahan baku yang dipakai untuk memproduksi spanduk 210 Meter selama satu bulan sebesar Rp. 2.920.000.

Tabel 4. Biaya Bahan Baku Pesanan Brosur (1.000 Lembar )

\begin{tabular}{|l|l|c|c|c|}
\hline No. & \multicolumn{1}{|c|}{ Keterangan } & Kebutuhan per Bulan & Biaya per Lembar & Jumlah \\
\hline 1. & Art Paper 150 gr & 1.000 Lembar & Rp. 1.000 per lembar & Rp. 1.000 .000 \\
\hline 2. & Tinta Ink & 2 Set & Rp. 600.000 & Rp. 1.200 .000 \\
\hline & Total & & & Rp. 2.200.000 \\
\hline
\end{tabular}

Sumber: CV. Satu Satu Media Utama

Tabel 4 menunjukkan biaya bahan baku yang dipakai untuk memproduksi brosur 1.000 Lembar selama satu bulan sebesar Rp. 2.200.000. 
Tabel 5. Biaya Tenaga Kerja Langsung Pesanan Spanduk (210 Meter)

\begin{tabular}{|l|l|c|r|c|c|}
\hline No. & Jenis Pekerjaan & Jumlah Karyawan & Upah per hari & Hari Kerja & Total \\
\hline 1. & Setting dan Desain & 1 Orang & Rp. 35.000 & 4 & Rp. 140.000 \\
\hline 2. & Printing & 1 Orang & Rp. 40.000 & 8 & Rp. 320.000 \\
\hline 3. & Finishing & 1 Orang & Rp. 30.000 & 4 & Rp. 120.000 \\
\hline & Total & & & Rp. 580.000 \\
\hline
\end{tabular}

Sumber: CV. Satu Satu Media Utama

Tabel 5 menunjukkan biaya tenaga kerja langsung selama pembuatan spanduk 210 Meter sebesar Rp. 580.000.

Tabel 6. Biaya Tenaga Kerja Langsung Pesanan Brosur (1.000 Lembar)

\begin{tabular}{|l|l|l|r|r|r|}
\hline No. & Jenis Pekerjaan & Jumlah Karyawan & Upah per hari & Hari Kerja & \multicolumn{1}{c|}{ Total } \\
\hline 1. & Setting dan Desain & 1 Orang & Rp. 35.000 & 1 & Rp. 35.000 \\
\hline 2. & Printing & 1 Orang & Rp. 40.000 & 3 & Rp. 120.000 \\
\hline 3. & Finishing & 1 Orang & Rp. 30.000 & 1 & Rp. 30.000 \\
\hline & Total & & & & Rp. 185.000 \\
\hline
\end{tabular}

Sumber: CV. Satu Satu Media Utama

Tabel 6 menunjukkan biaya tenaga kerja langsung selama pembuatan brosur 1.000 Lembar sebesar Rp. 185.000.

Tabel 7. Perhitungan Biaya Overhead Pabrik Selama 1 Bulan (168 Jam Kerja Mesin)

\begin{tabular}{|l|l|r|}
\hline \multicolumn{1}{|c|}{ No. } & \multicolumn{1}{|c|}{ Keterangan } & Jumlah \\
\hline 1. & Biaya Listrik & Rp. 1.500 .000 \\
\hline 2. & Biaya Sewa Gedung & Rp. 2.000 .000 \\
\hline 3. & Biaya Telepon & Rp. 200.000 \\
\hline 4. & Biaya Speady & Rp. 300.000 \\
\hline 5. & Biaya Adm dan umum (gaji karyawan adm) & Rp. 2.000 .000 \\
\hline 6. & Biaya Adm dan umum (biaya peralatan kantor) & Rp. 200.000 \\
\hline & Total biaya overhead & Rp. 6.200.000 \\
\hline
\end{tabular}

Sumber: CV. Satu Satu Media Utama

Perhitungan BOP selama 1 Bulan Jam Kerja Mesin sebagai berikut:

Biaya Overhead Pabrik :

Rp. 6.200.000 : 168 JKM 1 Bulan = Rp. 36.904 BOP per jam mesin

Perhitungan BOP untuk pesanan Spanduk 210 meter yaitu selama 48 jam kerja mesin sebagai brikut:

Tarif BOP : Rp. $36.904 \times 48$ JKM pesanan spanduk = Rp. 1.771 .392

Perhitungan BOP untuk pesanan brosur 1.000 lembar selama 26 jam mesin sebagai berikut:

Tarif BOP variabel: Rp. $36.904 \times 26$ JKM pesanan brosur $=$ Rp. 959.504 
Tabel 8. Perhitungan Harga Jual Produk Pesanan Spanduk dan Brosur

\begin{tabular}{|l|l|l|}
\hline \multicolumn{1}{|c|}{ Keterangan } & \multicolumn{1}{c|}{ Spanduk } & \multicolumn{1}{c|}{ Brosur } \\
\hline Biaya Bahan Baku & Rp. 2.920.000 & Rp. 2.200.000 \\
\hline Biaya Tenaga Kerja Langsung & Rp. 580.000 & Rp. 185.000 \\
\hline Biaya Overhead Pabrik & Rp. 1.771 .392 & Rp. 959.504 \\
\hline HPP & Rp. 5.271.392 & Rp. 3.344.504 \\
\hline $\begin{array}{l}\text { Ditambah laba yang diharapkan } \\
\text { perusahaan 10\% }\end{array}$ & Rp. 527.139 & Rp. 334.450 \\
\hline Total & Rp. 5.798.531 & Rp. 3.678.954 \\
\hline Harga jual per meter/lembar & Rp. 27.612 & Rp. 3.678 \\
\hline
\end{tabular}

Sumber: CV. Satu Satu Media Utama

\subsection{Pembahasan}

\section{Penerapan Sistem Job Order Costing}

a. Berdasarkan Pesanan. Sesuai dengan hasil penelitian bahwa perusahaan hanya memproduksi barang jika ada pesanan yang masuk. Job Order Costing menurut Firmansyah (2014 : 1) memang menjelaskan bahwa produk yang diproduksi berdasarkan pesanan konsumen. Dalam hal ini, perusahaan memang menjalankan sistem pesanan atau pengumpulan harga pokok produk sesuai dengan Job Order Costing.

b. Penggolongan Biaya Produksi. Penggolongan biaya produksi perusahaan telah sesuai dengan teori menurut Mulyadi (2015 : 38). Penggolongan biaya produksi terbagi atas biaya langsung dan biaya tidak langsung. Biaya langsung yang terdiri atas biaya bahan baku dan tenaga kerja langsung. Sedangkan biaya tidak langsung yaitu biaya overhead pabrik. Dalam perhitungan harga jual memang perusahaan memakai penggolongan biaya tersebut, namun perusahaan tidak menghitung biaya penyusutan mesin dan peralatan dan tidak memasukkan biaya pemasaran ke dalam perhitungan biaya overhead.

c. Harga Pokok Produk. Perhitungan harga pokok produk perusahaan tidak sesuai dengan sistem Job Order Costing karena perusahaan telah menentukan terlebih dahulu setiap barang yang diproduksi perusahaan dengan biaya per meter atau per lembar. Seharusnya dalam sistem Job Order Costing perusahaan menerima pesanan konsumen dan langsung menghitung harga jual produk berdasarkan pesanan yang diinginkan konsumen dengan menggunakan buku pembantu atau kartu harga pokok pesanan. Hal tersebut juga diungkapkan dalam penelitian terdahulu Nizar Fardani (2016) menjelaskan bahwa kartu harga pokok pesanan sangat penting guna mendokumentasikan dan merinci informasi biaya produksi sehingga dapat membantu perusahaan dalam pengambilan keputusan harga jual produk. 
Tabel 9. Perhitungan Biaya Penyusutan Mesin dan Peralatan Spanduk (210 Meter)

\begin{tabular}{|c|c|c|c|c|c|c|c|}
\hline \multirow[t]{2}{*}{ No. } & \multirow[t]{2}{*}{ Keterangan } & \multirow{2}{*}{$\begin{array}{c}\text { Jumlah } \\
\text { Unit }\end{array}$} & \multirow{2}{*}{$\begin{array}{c}\text { Harga } \\
\text { Perolehan } \\
\text { (Rp) }\end{array}$} & \multirow{2}{*}{$\begin{array}{l}\text { Nilai Sisa } \\
\quad \text { (Rp) }\end{array}$} & \multirow{2}{*}{$\begin{array}{c}\text { Umur } \\
\text { Ekonomis }\end{array}$} & \multicolumn{2}{|c|}{ Penyusutan } \\
\hline & & & & & & $\begin{array}{c}\text { Per } \\
\text { Tahun } \\
\text { (Rp) }\end{array}$ & $\begin{array}{c}\text { Per } \\
\text { Bulan } \\
(\mathbf{R p}) \\
\end{array}$ \\
\hline 1. & $\begin{array}{l}\text { Mesin } \\
\text { Digital } \\
\text { Printing }\end{array}$ & 1 & 120.000 .000 & 75.000 .000 & 8 Tahun & 5.625 .000 & 468.750 \\
\hline 2. & Komputer & 1 & 3.000 .000 & 1.000 .000 & 4 Tahun & 500.000 & 41.666 \\
\hline 4. & Gunting & 3 & 50.000 & - & 5 Tahun & 10.000 & 833 \\
\hline 5. & Meteran & 2 & 50.000 & - & 5 Tahun & 10.000 & 833 \\
\hline & Jumlah & & & & & 6.145 .000 & 42.673 \\
\hline
\end{tabular}

Sumber: Data Hasil Olahan

Dapat dilihat dari Tabel 9 biaya penyusutaan mesin dan peralatan menggunakan metode Garis Lurus (Straight Line Method) dengan rumus :

$$
\text { Biaya Penyusutan }=\frac{\text { Harga Perolehan }}{\text { Umur Ekonomis }}
$$

Tabel diatas juga menunjukkan bahwa jumlah biaya penyusutan mesin dan peralatan setiap bulannya sebesar Rp. 42.673. Semua peralatan dan mesin bukan hanya digunakan untuk pesanan spanduk saja melainkan digunakan juga untuk pesanan yang lain seperti poster, $\mathrm{x}$ banner dan neon box. Maka diambil $25 \%$ biaya penyusutan peralatan dan mesin untuk pembuatan spanduk ( 210 meter): $25 \%$ dari Rp. $42.673=$ Rp. 10.668.

Tabel 10. Perhitungan Biaya Penyusutan Mesin dan Peralatan Brosur (1.000 Lembar)

\begin{tabular}{|c|c|c|c|c|c|c|c|}
\hline \multirow[t]{2}{*}{ No. } & \multirow[t]{2}{*}{ Keterangan } & \multirow{2}{*}{$\begin{array}{c}\text { Jumlah } \\
\text { Unit }\end{array}$} & \multirow{2}{*}{$\begin{array}{c}\text { Harga } \\
\text { Perolehan } \\
(\mathbf{R p})\end{array}$} & \multirow{2}{*}{$\begin{array}{l}\text { Nilai Sisa } \\
\quad \text { (Rp) }\end{array}$} & \multirow{2}{*}{$\begin{array}{c}\text { Umur } \\
\text { Ekonomis }\end{array}$} & \multicolumn{2}{|c|}{ Penyusutan } \\
\hline & & & & & & $\begin{array}{c}\text { Per } \\
\text { Tahun } \\
(\mathbf{R p})\end{array}$ & $\begin{array}{c}\text { Per } \\
\text { Bulan } \\
\text { (Rp) }\end{array}$ \\
\hline 1. & Print & 1 & 1.500 .000 & 700.000 & 4 Tahun & 200.000 & 16.666 \\
\hline 2. & Komputer & 1 & 3.000 .000 & 1.000 .000 & 4 Tahun & 500.000 & 41.666 \\
\hline & Jumlah & & & & & 700.000 & 58.333 \\
\hline
\end{tabular}

Sumber: Data Hasil Olahan

Dapat dilihat dari Tabel 10 perhitungan biaya penyusutan brosur sama dengan perhitungan biaya penyusutan spanduk menggunakan metode garis lurus, bahwa jumlah biaya penyusutan mesin dan peralatan setiap bulannya sebesar Rp. 58.333. Semua peralatan dan mesin bukan hanya digunakan untuk pesanan brosur saja melainkan digunakan juga untuk pesanan kartu nama. Maka diambil $50 \%$ biaya penyusutan peralatan dan mesin untuk pembuatan brosur (1.000 lembar), diambil 50\% karena untuk mesin print dan komputer hanya digunakan khusus untuk cetak brosur dan kartu nama, 50\% dari Rp. $58.333=\mathbf{R p}$. 29.166 
Tabel 11. Perhitungan Biaya Overhead Pabrik Pesanan Spanduk

\begin{tabular}{|l|l|l|r|}
\hline No. & \multicolumn{1}{|c|}{ Keterangan } & Jenis Biaya & \multicolumn{1}{c|}{ Jumlah } \\
\hline 1. & Biaya Listrik & Variabel & Rp. 1.500 .000 \\
\hline 2. & Biaya Sewa Gedung & Tetap & Rp. 2.000 .000 \\
\hline 3. & Biaya Telepon & Variabel & Rp. 200.000 \\
\hline 4. & Biaya Speady & Variabel & Rp. 300.000 \\
\hline 5. & Biaya Adm dan Umum (gaji karyawan adm) & Tetap & Rp. 2.000 .000 \\
\hline 6. & Biaya Adm dan Umum (biaya peralatan kantor) & Variabel & Rp. 200.000 \\
\hline 7. & Biaya Pemasaran & Variabel & Rp. 200.000 \\
\hline 8. & Biaya penyusutan Mesin dan peralatan & Tetap & Rp. 10.668 \\
\hline & Total BOP variabel & & Rp. 2.400.000 \\
\hline & Total BOP tetap & & Rp. 4.010.668 \\
\hline
\end{tabular}

Sumber: Data Hasil Olahan

Biaya Overhead Pabrik Variabel:

Rp. 2.400.000 : 168 JKM 1 Bulan = Rp. 14.285 BOP per jam mesin

Rp. $14.285 \times 48$ JKM pesanan spanduk= RP. 685.680

Biaya Overhead Pabrik Tetap:

Rp. 4.010.668 : 168 JKM 1 Bulan = Rp. 23.873 BOP per jam mesin

RP. $23.873 \times 48$ JKM pesanan spanduk= RP. 1.145.904

Tabel 12. Perhitungan Biaya Overhead Pabrik Pesanan Brosur

\begin{tabular}{|l|l|l|r|}
\hline No. & \multicolumn{1}{|c|}{ Keterangan } & Jenis Biaya & \multicolumn{1}{c|}{ Jumlah } \\
\hline 1. & Biaya Listrik & Variabel & Rp. 1.500 .000 \\
\hline 2. & Biaya Sewa Gedung & Tetap & Rp. 2.000 .000 \\
\hline 3. & Biaya Telepon & Variabel & Rp. 200.000 \\
\hline 4. & Biaya Speady & Variabel & Rp. 300.000 \\
\hline 5. & Biaya Adm dan Umum (gaji karyawan adm) & Tetap & Rp. 2.000 .000 \\
\hline 6. & Biaya Adm dan Umum (biaya peralatan kantor) & Variabel & Rp. 200.000 \\
\hline 7. & Biaya Pemasaran & Variabel & Rp. 200.000 \\
\hline 8. & Biaya penyusutan Mesin dan peralatan & Tetap & Rp. 29.166 \\
\hline & Total biaya overhead variabel & & RP. 2.400.000 \\
\hline & Total biaya overhead tetap & & Rp. 4.029.166 \\
\hline
\end{tabular}

Sumber: Data Hasil Olahan

Biaya Overhead Pabrik Variabel:

Rp. 2.400.000 : 168 JKM 1 Bulan = Rp. 14.285 BOP per jam mesin

Rp. $14.285 \times 26 \mathrm{JKM}$ pesanan brosur $=$ RP. 371.410

Biaya Overhead Pabrik Tetap:

Rp. 4.029.166 : 168 JKM 1 Bulan = Rp. 23.983 BOP per jam mesin

RP. $23.983 \times 26 \mathrm{JKM}$ pesanan brosur $=$ RP. 623.558 


\begin{tabular}{|c|c|c|c|}
\hline \multicolumn{4}{|c|}{ Tabel 13. Perbandingan Perhitungan Harga Jual Pesanan Spanduk (210 Meter) } \\
\hline Keterangan & Perusahaan & Full Costing & Variable Costing \\
\hline Biaya Bahan Baku & Rp. 2.920 .000 & Rp. 2.920 .000 & Rp. 2.920 .000 \\
\hline Biaya Tenaga Kerja Langsung & Rp. 580.000 & Rp. 580.000 & Rp. 580.000 \\
\hline Biaya Overhead Pabrik Variabel & Rp. 628.560 & Rp. 685.680 & Rp. 685.680 \\
\hline Biaya Overhead Pabrik Tetap & Rp. 1.142 .832 & Rp. 1.145.904 & \\
\hline HPP & Rp. 5.271.392 & Rp. 5.331.584 & Rp. 4.185.680 \\
\hline $\begin{array}{l}\text { Ditambah laba yang diharapkan } \\
\text { perusahaan } 10 \%\end{array}$ & Rp. 527.139 & Rp. 533.158 & Rp. 418.568 \\
\hline Total & Rp. 5.798.531 & Rp. 5.864.742 & Rp. 4.604 .248 \\
\hline Harga jual per meter & Rp. 27.612 & Rp. 27.927 & Rp. 21.924 \\
\hline
\end{tabular}

Sumber: Data Hasil Olahan

Tabel 14. Perbandingan Perhitungan Harga Jual Pesanan Brosur (1.000 Lembar)

\begin{tabular}{|l|r|r|r|}
\hline \multicolumn{1}{|c|}{ Keterangan } & \multicolumn{1}{c|}{ Perusahaan } & \multicolumn{1}{c|}{ Full Costing } & \multicolumn{1}{c|}{ Variable Costing } \\
\hline Biaya Bahan Baku & Rp. 2.200 .000 & Rp. 2.200 .000 & Rp. 2.200.000 \\
\hline Biaya Tenaga Kerja Langsung & Rp. 185.000 & Rp. 185.000 & Rp. 185.000 \\
\hline Biaya Overhead Pabrik Variabel & Rp. 340.470 & Rp. 371.410 & Rp. 371.410 \\
\hline Biaya Overhead Pabrik Tetap & Rp. 619.034 & Rp. 623.558 & - \\
\hline HPP & Rp. 3.344.504 & Rp. 3.379.734 & Rp. 2.756.410 \\
\hline $\begin{array}{l}\text { Ditambah laba yang diharapkan } \\
\text { perusahaan 10\% }\end{array}$ & Rp. 334.450 & Rp. 337.973 & Rp. 275.641 \\
\hline Total & Rp. 3.678.954 & Rp. 3.717.707 & Rp. 3.032.051 \\
\hline Harga jual per lembar & Rp. 3.678 & Rp. 3.717 & Rp. 3.032 \\
\hline
\end{tabular}

Sumber: Data Hasil Olahan

\section{KESIMPULAN DAN SARAN}

\subsection{Kesimpulan}

Berdasarkan hasil penelitian tentang penerapan Job Order Costing dalam penentuan harga jual produk perusahaan, maka penulis dapat mengambil beberapa kesimpulan yaitu:

1. Perusahaan dalam penerapan sistem Job Order Costing, berdasarkan pesanan dan penggolongan biaya telah sesuai dengan teori yang ada. Namun, perusahaan tidak menghitung harga pokok produk sesuai dengan pesanan atau dihitung langsung pada saat pesanan masuk.

2. CV. Satu Satu Media Utama dalam perhitungan harga pokok produk belum menghitung secara teliti untuk penentuan harga jual poduk. Perhitungan biaya overhead yang tidak memasukkan biaya pemasaran dan biaya penyusutan mesin serta tidak membagi biaya overhead untuk pesanan spanduk dan pesanan brosur, karena biaya overhead bukan hanya untuk pesanan spanduk dan brosur saja melainkan untuk semua pesanan barang perusahaan dalam satu bulan.

3. Perusahaan belum menerapkan sistem Job Order Costing, karena perusahaan telah menetapkan harga per meter atau per lembar sehingga setiap pesanan yang masuk telah dihitung terlebih dahulu harga jual barang tersebut.

\subsection{Saran}

Berdasarkan hasil analisis dan kesimpulan, maka penulis dapat memberikan saran sebagai berikut:

1. Perusahaan untuk sistem penerapan Job Order Costing harus menghitung harga pokok produk berdasarkan pesanan yang masuk dengan menggunakan kartu pembantu atau kartu harga pokok pesanan. 
2. Perusahaan dalam menetapkan harga jual sebaiknya menggunakan metode Full Costing untuk spanduk Rp. 27.927 per meter dan untuk brosur Rp. 3.717 per lembar. Perhitungan menggunakan metode Full Costing lebih akurat karena memasukkan seluruh BOP variabel dan tetap.

3. Dalam perhitungan harga pokok produk sebaiknya perusahaan memiliki bagian keuangan agar dapat mengontrol dan menghitung seluruh biaya dengan tepat. Perhitungan harga pokok produk dengan menggunakan metode pengumpulan Job Order Costing, perusahaan harus mempunyai buku pembantu kartu harga pokok untuk setiap pesanan yang masuk agar mempermudah dalam perhitungan harga pokok produk. Kartu harga pokok pesanan lebih rinci dibandingkan nota pembayaran yang dibuat perusahaan untuk setiap pesanan yang masuk. Kartu harga pokok pesanan harus menghitung seluruh biaya pokok untuk setiap pesanan seperti: biaya bahan baku, tenaga kerja langsung dan biaya overhead pabrik, sehingga dapat mempermudah perusahaan dalam menghitung harga pokok produksi dan memberikan harga jual yang tepat kepada konsumen.

\section{DAFTAR PUSTAKA}

Bustami, B dan Nurlela. 2013. Akuntansi Biaya. Edisi Keempat. Jakarta : Mitra Wacana Media.

Firmansyah. 2014. Akuntansi Biaya itu Gampang. Cetakan Pertama. Dunia Cerdas, Jakarta.

Hans Kartikahadi. 2016. Akuntansi Keuangan Berdasarkan SAK Berbasis IFRS Buku 1. Jakarta: Salemba Empat.

Horngren, Datar, Foster, George. 2009. Akuntansi Biaya dengan Penekanan Manajerial. Jilid

1. Edisi keduabelas. Erlanggga, Jakarta.

Mulyadi. 2014. Akuntansi Biaya. UPP STIM YKPN, Yogyakarta.

Mulyadi. 2015. Akuntansi Biaya. Edisi kelima. Cetakan ketigabelas. UPP STIM YKPN, Yogyakarta.

Rudianto. 2013. Akuntansi Manajemen: Informasi Untuk Pengambilan Keputusan Strategis. Jakarta: Erlangga.

Salman, Kautzar Riza, dan Mochammad Farid. 2017. Akuntansi Manajemen. Jakarta: Indeks.

Siregar, Baldric, Suripto, Bambang. 2013. Akuntansi Biaya. Edisi Pertama. Jakarta: Salemba Empat.

Sugiyono. 2015. Metode Penelitian Kuantitatif Kualitatif dan R\&D. Bandung: Alfabeta.

Supriyono, R.A. 2013. Akuntansi Biaya: pengumpulan biaya dan penentuan harga pokok. Yogyakarta: BPFE.

William K. Carter dan Usry, Milton F. 2014. Akuntansi Biaya, Diterjemahkan Oleh Krista. Buku Satu, Edisi ke Empatbelas. Jakarta: Salemba Empat. 